\title{
Evolution of physical performance in professional soccer across four consecutive seasons
}

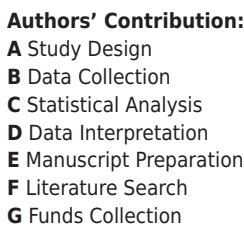

\author{
Łukasz Radzimiński ABCDEFG, Zbigniew Jastrzębski ADEFG \\ Department of Physiology and Biochemistry, \\ Gdansk University of Physical Education and Sport, Gdansk, Poland
}

\section{abstract}

Background: Main purpose of this research was to investigate the changes of physical match performance in Polish Ekstraklasa across four consecutive seasons.

Material and methods: A total of 949 official matches from season 2017/2018 to 2020/2021 were analyzed. Such match running performance variables as total distance, high-speed running, sprinting, and number of high-intensity runs were involved. Each season data were divided into two rounds (spring round and autumn round). Due to the pandemic of COVID-19 additional post-lockdown round (Spring I 2019/2020) occurred.

Results: Comparison in the results between Spring 2017/2018 and Spring 2020/2021 indicated significant increases in total distance $(2.1 \%, \mathrm{p}<0.001)$, high-speed running $(11.9 \%, \mathrm{p}<0.001)$, sprinting distance $(7.7 \%, p<0.01)$ and number of high-intensity runs $(9.7 \%, p<0.001)$. Moreover, within season analysis exhibited that during spring rounds Ekstraklasa teams covered significantly longer $(p<0.01)$ distances in high-speed running than during autumn rounds. Reduction in physical match performance was reported after the 12-week pandemic lockdown.

Conclusions: The results of this study confirmed the growing importance of such match activities as high-speed running, sprinting and number of high intensity runs which increased in Polish Ekstraklasa by $8-12 \%$ within last 4 years. This growing tendency was disrupted by unexpected off-season period caused by COVID-19 lockdown.

Key words: soccer, match performance, time-motion analysis, Polish Ekstraklasa.

\section{article details}

Article statistics: Word count: 2,141; Tables: 1; Figures: 2; References: 27

Received: July 2021; Accepted: September 2021; Published: September 2021

Full-text PDF:

http://www.balticsportscience.com

Copyright ๑ Gdansk University of Physical Education and Sport, Poland

Indexation: Celdes, Clarivate Analytics Emerging Sources Citation Index (ESCI), CNKI Scholar (China National Knowledge Infrastructure), CNPIEC, DOAJ, EBSCO - Central \& Eastern European Academic Source, EBSCO - SPORTDiscus, EBSCO Discovery Service, Google Scholar, Index Copernicus, J-Gate, Naviga (Softweco, Primo Central (ExLibris), ProQuest - Family Health, ProQuest - Health \& Medical Complete, ProQuest - Illustrata: Health Sciences, ProQuest Nursing \& Allied Health Source, Summon (Serials Solutions/ProQuest, TDOne (TDNet), Ulrich's Periodicals Directory/ ulrichsweb, WorldCat (OCLC)

Funding: This research received no specific grant from any funding agency in the public, commercial, or not-for-profit sectors.

Conflict of interests: Corresponding author:

Open Access License:
Authors have declared that no competing interest exists.

Łukasz Radzimiński PhD, Gdansk University of Physical Education and Sport, K. Górskiego 1, 80-336 Gdańsk; e-mail; lukasz.radziminski@wp.pl; tel. +48585547121

This is an open access article distributed under the terms of the Creative Commons Attribution-Non-Commercial-NoDerivatives 4.0 International (https://creativecommons.org/licenses/by-nc-nd/4.0/), which permits use, distribution, and reproduction in any medium, provided the original work is properly cited, the use is non-commercial and is otherwise in compliance with the license. 


\section{INTRODUCTION}

Soccer is one of the most popular sports in the world. Due to the development of available technologies there is still growing interest in the research concerning the physical match performance. Over the past twenty years numerous studies investigated the running demands of the official soccer games [1-3]. Distance covered by the players is dependent on several variables such as playing position [4], match outcome [5], players body composition [6] or their physical fitness [7].

Conventional time-motion analysis usually involve data of total distance (TD), distance covered in different speed zones and number of high-intensity runs or sprints. However, the definitions of kinematic zones vary widely. Several previous studies highlighted the necessity of unifying the division of the most commonly used speed zones or to individualize the data according to players potential $[8,9]$. The homogenous criteria of setting the time-motion ranges would allow coaches and sport scientists for reliable comparison of analysis from different researches. Moreover, such analysis could establish the physical demands of soccer players from different levels of competition.

The evolution of soccer match performance have been previously investigated in certain leagues. Barnes et al. [10] analyzed the changes in physical demands of English Premier League across 7-season period. It was established that although the total distance covered by the players was relatively constant, the high-intensity running and sprinting distance increased by 30-35\%. Recent analyses by Zhou et al. [11, 12] reported the changes of technical and physical performance during official matches in Chinese Soccer Super League registered form season 2012 to season 2017. Similarly to Barnes et al. [10] TD remained stable, while high-speed running and sprinting performance increased during investigated period of time. Furthermore, the negative effect of total distance in possession on the winning the game and positive effect of total distance out of possession on winning the match in Chinese League was detected. These studies clearly indicate that physical demands of modern soccer are still evolving.

Although, there has been growing interest in the competition of Polish Ekstraklasa, the number of scientific papers examining the physical match performance in this league is still very limited [13]. Previous researches concerned such topics as training loads [14] or changes in selected blood parameters across the season [15]. To our best knowledge no longitudinal study investigated the changes of physical match performance in Polish Ekstraklasa to date. Following the potential evolution of soccer match requirements provide numerous practical information for soccer coaches and is very useful for preparing the training programs. Therefore, the main purpose of this study was to investigate the physical demands of professional soccer players, and to identify potential changes in physical match performance in Polish Ekstraklasa teams across four consecutive seasons. Based on previous research it was hypothesized that increasing trends of high-intensity performance will be detected.

\section{MATERIAL AND METHODS}

\section{DESIGN}

A total of 949 official Polish Ekstraklasa (highest level of competition in Poland) matches from season 2017/2018 to 2020/2021 were analysed in the study. The competitive season in Polish Ekstraklasa consists of 2 rounds: Autumn round (from July to December) and Spring round (from February to May). Break between the rounds typically lasts from 7 to 9 weeks. For this reason analysing the data divided into two round seems to be justified. Due to uncompleted data only spring round of season 2017/2018 was taken into consideration 
in current research. Furthermore, because of the COVID-19 pandemic lockdown the schedule of season 2019/2020 was modified. After 6 matchdays of the Spring round the competition was suspended and the season restarted at the beginning of May, after 81days lockdown. Therefore, the spring round of season 2019/2020 was divided into two rounds: Spring I (before the lockdown) and Spring II (after season resumption). Between seasons 2017/2018 and 2019/2020 Ekstraklasa was played according to ESA 37 system involving 37 matchdays. After elongated 2019/2020 season, during 2020/2021 competition each team completed only 30 matchdays. Detailed schedule of the analysed seasons is presented in Figure 1.

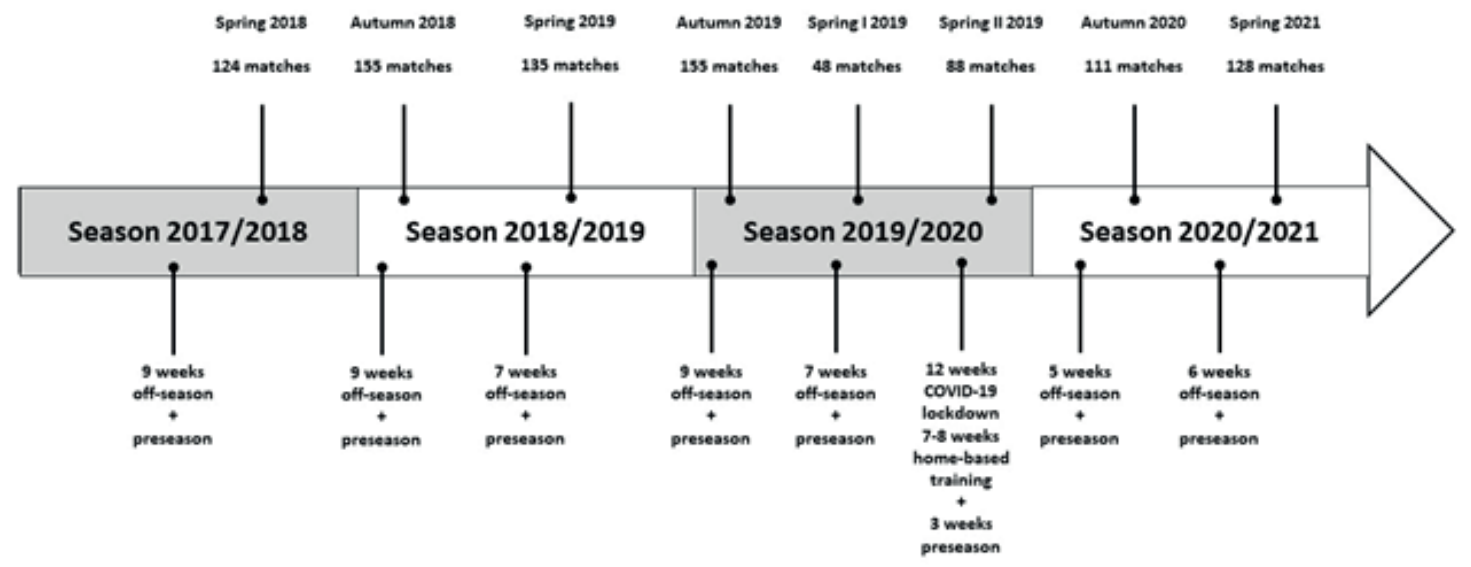

Fig. 1. The timeline of competition and preseason periods from season 2017/2018 to 2020/2021 in Polish Ekstraklasa

\section{DATA COLLECTION}

The data used physical match performance was obtained from a third-party, https:// tracabportal.azurewebsites.net/login, using computerised multiple-camera optical tracking system TRACAB ${ }^{\circledR}$ (ChryronHego VID, New York, NY) with sampling frequency of $25 \mathrm{~Hz}$, which was previously validated [16]. The data was provided under scientific cooperation with a football clubs currently appearing in Polish Ekstraklasa. The metadata would allow someone else to re-identify teams and possibly players. However, access to the data should be possible from the third-party. The data acquired were so called 'excel dumps' of player statistics per match. Access to the data can be organized by contacting Match Analysis Hub: info@chyronhego.com.

The match running performance was divided into the following categories: total distance covered (TD), high-speed running (HSR, 19.8-25.1 km· $\mathrm{h}^{-1}$ ), sprinting $\left(>25.2 \mathrm{~km} \cdot \mathrm{h}^{-1}\right)$. Presented division of the speed zones was in line with Di Salvo et al. [4]. The total number of high-speed runs and total number of sprint was defined as a number of high-intensity actions (NHIR). Moreover the data of effective playing time (Et), which is defined as duration of play after subtracting the time taken up by all stoppages - when ball is out of play [17] were presented in the study as well.

\section{STATISTICAL ANALYSIS}

The results are presented as means \pm standard deviations and 95\% confident intervals. The one-way analysis of variance (ANOVA) for independent variables was used to detect potential differences between the rounds. Pairwise comparisons were conducted via Honest Significant Difference Tukey's post-hoc test for unequal sample sizes. The significance level was set at $\mathrm{p}<0.05$. All the analysis were performed using the STATISTICA software version 13.0 (TIBCO Software Inc, 2017). 


\section{RESULTS}

The duration of the match varied between 96.0 and 97.2 minutes, while $\mathrm{E}_{\mathrm{t}}$ was in the range between 54.3 and 56.3 minutes. Thus, $\mathrm{E}_{\mathrm{t}}$ comprised between 56.2 and $58.6 \%$ of total match time. Changes in physical performance variables are presented in Table 1 and Figure 2.

Table 1. Means and standard deviations of match duration, effective playing time and physical performance variables in Polish Ekstraklasa across four consecutive seasons

\begin{tabular}{|c|c|c|c|c|c|c|c|c|}
\hline & \multirow{2}{*}{$\begin{array}{c}\text { Season } \\
2017 / 2018 \\
\begin{array}{c}\text { Spring } 2018 \\
(n=124)\end{array}\end{array}$} & \multicolumn{2}{|c|}{ Season $2018 / 2019$} & \multicolumn{3}{|c|}{ Season $2019 / 2020$} & \multicolumn{2}{|c|}{ Season $2020 / 2021$} \\
\hline & & $\begin{array}{l}\text { Autumn } 2018 \\
\quad(n=155)\end{array}$ & $\begin{array}{l}\text { Spring } 2019 \\
\quad(n=135)\end{array}$ & $\begin{array}{l}\text { Autumn } 2019 \\
\quad(n=160)\end{array}$ & $\begin{array}{c}\text { Spring I } 2020 \\
\quad(n=48)\end{array}$ & $\begin{array}{c}\text { Spring II } 2020 \\
\quad(n=88)\end{array}$ & $\begin{array}{l}\text { Autumn } 2020 \\
\quad(n=111)\end{array}$ & $\begin{array}{l}\text { Spring } 2021 \\
\quad(n=128)\end{array}$ \\
\hline $\begin{array}{l}\text { Match } \\
\text { duration [min] }\end{array}$ & $96.2 \pm 2.8$ & $96.4 \pm 2.1$ & $97.2 \pm 2.9^{* \#}$ & $96.9 \pm 2.4^{*}$ & $97.1 \pm 2.9$ & $96.2 \pm 2.3^{\dagger}$ & $96.4 \pm 3.2^{\dagger}$ & $96.0 \pm 2.3^{\text {ta }}$ \\
\hline$E_{t}[\min ]$ & $54.3 \pm 5.2$ & $55.2 \pm 4.5$ & $54.6 \pm 4.9$ & $56.0 \pm 4.7^{*+}$ & $55.7 \pm 5.0$ & $56.3 \pm 4.6^{*+}$ & $56.1 \pm 5.3^{*+}$ & $56.0 \pm 4.7^{* \dagger}$ \\
\hline TD $[\mathrm{km}]$ & $111.6 \pm 4.3$ & $112.7 \pm 4.5$ & $113.1 \pm 4.4^{*}$ & $112.3 \pm 4.4$ & $114.5 \pm 3.6^{* \neq}$ & $111.7 \pm 4.6^{\text {s* }}$ & $112.8 \pm 4.4$ & $114.0 \pm 4.4^{* \# \neq \varepsilon}$ \\
\hline Sprinting [m] & $1689.1 \pm 362.8$ & $1759.0 \pm 369.9$ & $1768.6 \pm 352.9$ & $1738.5 \pm 362.3$ & $1800.7 \pm 339.2$ & $1720.6 \pm 332.6$ & $1784.9 \pm 360.8$ & $1819.7 \pm 362.5^{*}$ \\
\hline $\begin{array}{l}\text { Relative TD } \\
{[\mathrm{m} / \mathrm{min}]}\end{array}$ & $1160.6 \pm 49.8$ & $1169.3 \pm 52.0$ & $1164.2 \pm 52.3$ & $1160.2 \pm 51.7$ & $1180.3 \pm 47.6$ & $1164.1 \pm 45.3$ & $1171.3 \pm 56.0^{* \dagger}$ & $1187.5 \pm 50.0^{* \#+\neq \& \#}$ \\
\hline $\begin{array}{l}T D / E_{t} \\
{[\mathrm{~m} / \mathrm{min}]}\end{array}$ & $2074.7 \pm 192.9$ & $2051.5 \pm 15.2$ & $2084.8 \pm 163.6^{*+}$ & $2018.1 \pm 154.2$ & $2071.6 \pm 170.6$ & $1998.1 \pm 158.7^{* \#+\$}$ & $2026.6 \pm 171.4$ & $2049.5 \pm 160.6^{\&}$ \\
\hline
\end{tabular}

* significantly different from Spring 2017/2018; \# significantly different from Autumn 2018/2019; ${ }^{\text {significantly }}$ different from Spring 2018/2019; ₹ significantly different from Autumn 2019/2020; \$ significantly different from Spring I 2019/2020; \& significantly different from Spring II 2019/2020; ${ }^{*}$ significantly different from Autumn 2020/2021; $E_{t}$ effective playing time, TD - total distance.

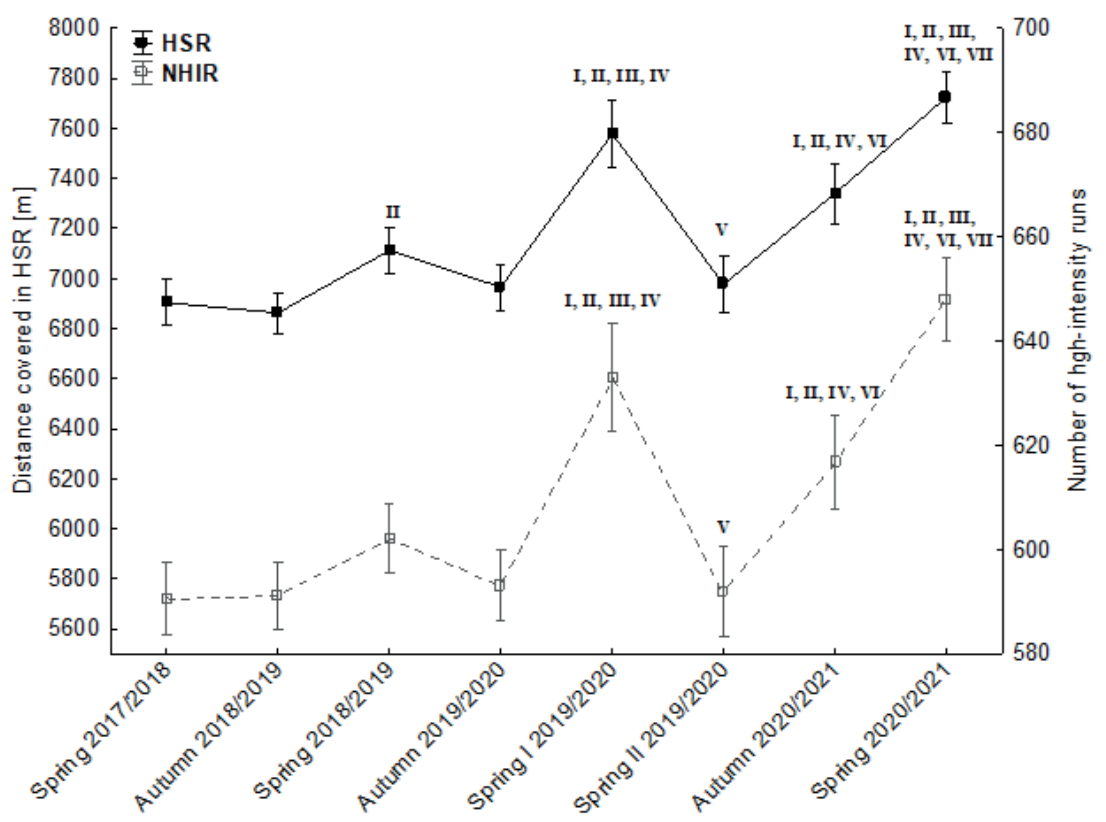

Fig. 2. Changes in HSR and NHIR (means and 95\% confident intervals) across four seasons in Polish Ekstraklasa. Significantly different from: I - Spring 2017/2018; II - Autumn 2018/2019; III - Spring 2018/2019; IV - Autumn 2019/2020; V - Spring I 2019/2020; VI - Spring II 2019/2020; VII - Autumn 2020/2021

The average total distance covered by the Ekstraklasa teams in Spring 2020/2021 was 2.1\% (114.0 km vs $111.6 \mathrm{~km}, \mathrm{p}<0.001$ ) longer than during Spring 2017/2018. Moreover, further analysis between Spring 2017/2018 and Spring 2020/2021 demonstrated significant increases in HSR (11.9\%, p<0. 001), sprinting distance $(7.7 \%, \mathrm{p}<0.01)$ and NIHR $(9.7 \%$, $\mathrm{p}<0.001$ ). A comparative analysis of two rounds within one season exhibited that during the spring rounds (seasons from 2018/2019 to 2020/2021) Ekstraklasa teams covered significantly longer $(\mathrm{p}<0.01)$ distances in HSR than during autumn rounds of the same 
seasons. Similar effect was observed for sprinting distance and NHIR, however the significance level of differences was not reached for all analyzed seasons. Furthermore, the significant reduction in physical match performance was reported after the 12-week pandemic lockdown. During second part of spring round 2019/2020 covered significantly shorter TD $(2.3 \%, \mathrm{p}<0.001)$, HSR distance $(8.0 \%, \mathrm{p}<0.001)$, NHIR $(6.5 \%, \mathrm{p}<0.001)$ and TD/Et (3.6\%, p<0.05) in comparison with Spring I 2019/2020.

\section{DISCUSSION}

This is the first longitudinal research analyzing the evolution of physical performance in Polish Ekstraklasa. Present study aimed to identify potential changes and trends in match kinematics in professional soccer across four consecutive seasons. The results highlighted the nonlinear increases across four seasons in such variables as HSR distance, sprinting distance and NHIR. Moreover, significant differences between spring and autumn round of the same season were reported. Finally, the potential negative effect of pandemic lockdown on the physical match performance was detected as well.

Improvements in high-intensity match activities exhibited in current study across the analyzed period in Polish Ekstraklasa are in line with previous studies of Barnes et al. [10] and Bush et al. [18] who reported even larger increases in English Premier League between seasons 2006/2007 and 2012/2013. Results presented in these studies demonstrated that distance covered in sprinting and HSR increased by 30-55\% and 29-33\% respectively, while in Polish Ekstraklasa these improvements were between 8\% and 12\%. Different magnitude of changes were probably caused by longer analyzed period of time in Premier League the in Ekstraklasa (7 seasons vs 4 seasons). Similar comparison was presented by Zhou et al. [11] who displayed the data of physical and technical indicators of Chinese Soccer Super League across 6 seasons. This analysis exhibited significant differences between season 2012 and 2017 in total sprinting distance (9.8\%), number of sprints (4.7\%) and high-speed running (9.9\%). Although, different speed zones (high-speed running: $19.1-23 \mathrm{~km} \cdot \mathrm{h}^{-1}$; sprinting: $>23.1$ $\mathrm{km} \cdot \mathrm{h}^{-1}$ ) were applied in this research, the direction of change is in line with our results.

The changes of physical match demands in professional soccer should be supported by modifications in the training process. Adjusting the weekly training load according to the demands of modern soccer seems to be a crucial task for coaches and sport scientists. Systematically increasing number of high-intensity actions during the match may contribute to larger hamstring injury occurrence. Nevertheless, some authors exhibited that training may not follow the game requirements correctly. Although the ankle sprain occurrence decreased significantly, [19] the hamstring injury rates have increased [20]. Moreover, the annual increase in the ACL injury rate in professional soccer players was reported [21]. These trends may suggest that insufficient number of such prevention exercises as hamstring eccentric work and balance/proprioception exercises is applied to professional soccer players.

A comparison of the physical performance between the rounds showed that match activity in Polish Ekstraklasa teams is higher the spring round the during the autumn season. Nowakowska et al. [15] analysed the changes of selected blood parameters in Polish Ekstraklasa players along the competitive season. Interestingly, higher values of creatine kinase (CK) were obtained after the matches played during the spring round. It is widely known that CK leaks in the plasma from skeletal muscle fibres during exercises characterized by repeated intensive muscle contractions [22]. Soccer match that involves numerous stop-and-go movements, sprints and changes of direction is undoubtedly such an exercise [23]. Thus, larger number of high-intensity actions performed in the spring rounds could possibly explain higher activity of CK in Ekstraklasa players during this part of the season. Chmura et al. [24] compared the running performance of German Bundesliga 
players in spring and autumn round. They showed that distance covered with velocity above $4 \mathrm{~m} \cdot \mathrm{s}^{-1}\left(14.4 \mathrm{~km} \cdot \mathrm{h}^{-1}\right)$ was higher during the spring round then while autumn round. This effect is in agreement with the results presented in the current research. However, differences in the competition schedule (e.g. different duration of the between-rounds period) between the leagues should be taken into consideration.

Due to unexpected 12-week off-season period that occurred because of the COVID-19 lockdown, the spring round 2019/2020 was splitted into two sub-rounds. Such division clearly exhibited the negative influence of the unplanned season suspension on the physical match performance. The values of the time-motion variables (TD, HSR, sprinting distance, NHIR, relative TD and TD/E $\mathrm{E}_{\mathrm{t}}$ ) recorded during Spring II were lower in comparison with preceding (Spring I 2019/2020) and following round (Autumn 2020/2021). Moreover, the increasing trend of high-intensity activities (HSR, sprinting, NHIR) was disrupted during post-lockdown period. Furthermore, the lowest NHIR and TD/Et among the entire analysed period were displayed exactly in the Spring II 2019/2020. The deterioration of physical match performance after the COVID-19 lockdown was confirmed by Garcia-Aliaga et al. [25] who demonstrated significant decrease in TD, HSR per minute, sprinting distance and number of high-intensity actions in Spanish LaLiga teams after the season resumption. This effect was expected by the international experts form sport science area who expressed their concerns about the lockdown impact on the high-intensity actions performed during the soccer match [26]. Such reductions in Polish Ekstraklasa teams were possibly caused by long-term (8 weeks) home-based training period and very short pre-season (1 week of soccer training in small groups followed by 18 days of typical team soccer training).

This study demonstrated the evolution of physical performance in Polish Ekstraklasa for the first time. Nevertheless, some limitations are worth to mention. Last three rounds where played without or with limited number spectators on the stadiums. Although Tlip \& Thaller [27] found that it can affect the match outcome, the effect lacking audience on physical performance is still unknown. Moreover, after the pandemic lockdown (Spring II 2020) the number of allowed substitutions increased up to five. To the authors best knowledge there are no available studies analyzing the influence of this change on team physical performance. However, it cannot be excluded that such rule modification could impact the teams' activity during the game. Future research should contain the analysis of accelerations and decelerations during the official matches, as these variables are considered to be very important in enhancing the fatigue during the exercise.

\section{CONCLUSIONS}

Presented in current study results confirmed the growing importance of such match activities as HSR, sprinting and NHIR which increased in Polish Ekstraklasa by 8-12 \% within last 4 years. Although this tendency was inhibited by unexpected off-season period caused by the COVID-19 lockdown, the following season exhibited further increases in high-intensity activities. These data provide numerous practical application for sport scientists and coaches. Longer distance covered by the players in HSR and sprinting during the matches should be accompanied by appropriate training modifications. Thus, each weekly microcycle should contain efforts developing repeated sprint ability and prevention drills including eccentric exercises for hamstrings which can effectively protect muscles from potential injuries.

\section{REFERENCES}

[1] Clemente JAA, Requena B, Jukic I, Nayler J, Santall Hernandez A, Carling C. Is physical performance a differentiating element between more or less successful football teams? Sports (Basel) 2019;7(10):216. https://doi.org/10.3390/ sports7100216

[2] Mohr M, Krustrup P and Bangsbo J. Match performance of high standard soccer players with special reference to development of fatigue. J Sports Sci. 2003;21:519-28. https://doi.org/10.1080/0264041031000071182 
[3] Rampinini E, Coutts AJ, Castagna C, Sassi R, Impellizzeri FM.. Variation in top level soccer match performance. Int J Sports Med. 2007;28(12):1018-1024. https://doi.org/10.1055/s-2007-965158

[4] Di Salvo V, Gregson W, Atkinson G, Tordoff P, Drust B. Analysis of high-intensity activity in Premier League Soccer. Int J Sports Med. 2009;30(3):205-2012. https://doi.org/10.1055/s-0028-1105950

[5] Andrzejewski M, Konefał M, Chmura P, Kowalczuk E, Chmura J. Match outcome and distances covered at various speeds in match play by elite German soccer players. Int J Perf Anal Sports 2016;16(3):817-28. https://doi.org/10.1 080/24748668.2016.11868930

[6] Radzimiński Ł, Szwarc A, Padrón-Cabo A, Jastrzębski Z.. Correlations between body composition, aerobic capacity, speed and distance covered among professional soccer players during official matches. J Sports Med Phys Fitness 2020;60(2):257-62. https://doi.org/10.23736/S0022-4707.19.09979-1

[7] Redkva PE, Paes MR, Fernandez R, da Silva SG. Correlation between match performance and field tests in professional soccer players. J Hum Kinet. 2018;62:213-19. https://doi.org/10.1515/hukin-2017-0171

[8] Abt G, Lovell R. The used of individualized speed and intensity threshold for determining the distance run at highintensity in professional soccer. J Sports Sci. 2009;27:893-98. https://doi.org/10.1080/02640410902998239

[9] Jastrzębski Z, Radzimiński Ł. Individual vs General Time-Motion Analysis and Physiological Response in 4 vs 4 and 5 vs 5 Small-Sided Games. Int J Perf Anal Sport 2015;15:397-410. https://doi.org/10.1080/24748668.2015.11868801

[10] Barens C, Archer DT, Hogg B, Bush M, Bradley PS. The evolution of physical and technical performance parameters in the English Premier League. Int J Sports Med. 2014;35(13):1095-1100. https://doi.org/10.1055/s-0034-1375695

[11] Zhou C, Gomez MA, Lorenzo A. The evolution of physical and technical performance parameters in the Chinese Soccer Super League. Biol Sport 2020;37(2):139-45. https://doi.org/10.5114/biolsport.2020.93039

[12] Zhou C, Lorenzo Calvo A, Robertson S, Gómez MA. Long-term influence of technical, physical performance indicators and situational variables on match outcome in male professional Chinese soccer. J Sports Sci. 2021;39(6):598-608. https://doi.org/10.1080/02640414.2020.1836793

[13] Andrzejewski M, Pluta B, Konefał M, Konarski J, Chmura J, Chmura P. Activity profile in elite Polish soccer players. Res Sports Med. 2019;24(4):473-84. https://doi.org/10.1080/15438627.2018.1545648

[14] Radzimiński Ł, Jastrzębski Z, Lopez-Sanchez GF, et al. Relationships between training loads and selected blood parameters in professional soccer players during a 12-day sports camp. Int J Environ Res Public Health 2020;17(22):8580. https://doi.org/10.3390/ijerph17228580

[15] Nowakowska A, Kostrzewa-Nowak D, Buryta R, Nowak R.. Blood biomarkers of recovery efficiency in soccer players. Int J Environ Res Public Health. 2019;16(18):3279. 10.3390/ijerph16183279

[16] Linke D, Link D, Lames M. Football-specific validity of TRACAB's optical video tracking systems. PloS One. 2020;15:e0230179. https://doi.org/10.1371/journal.pone.0230179

[17] Castellano J, Blanco-Villasenor A, Alvarez D. Contextual variables and time-motion analysis in soccer. Int J Sports Med. 2011;32:415-21. https://doi.org/10.1055/s-0031-1271771

[18] Bush M, Archer DT, Barnes C, Hogg B, Bradley PS. Longitudinal match performance characteristics of UK and nonUK players in the English Premier League. Sci \& Med Football. 2017;1(1):2-9. https://doi.org/10.1080/02640414.2 016.1233347

[19] Walden M, Hagglud M, Ekstrand J. Time-trends and circumstances surrounding ankle injuries in men's professional football: An 11-year follow-up of the UEFA Champions League injury study. Brit J Sports Med. 2013;47(12):748-53. https://doi.org/10.1136/bjsports-2013-092223

[20] Ekstrand J, Walden M, Hagglud M. Hamstring injuries have increased by 4\% annually in men's professional football, since 2001: A 13-year longitudinal analysis of the UEFA Elite Club injury study. Brit J Sports Med. 2016;50(12):73137. https://doi.org/10.1136/bjsports-2015-095359

[21] Walden M, Hagglud M, Magnusson H, Ekstrand J. ACL injuries in men's professional football: A 15-year prospective study on time trends and return-to-play rates reveals only 65\% of players still play at top level 3 years after ACL rapture. Brit J Sports Med. 2016;50(12):744-50. https://doi.org/10.1136/bjsports-2015-095952

[22] Mougios V. Reference intervals for serum creatine kinase in athletes. Brit J Sports Med. 2007;41:674-678. https:// doi.org/10.1136/bjsm.2006.034041

[23] Mayer T, Meister S. Routine blood parameters in elite soccer players. Int J Sports Med. 2011;32(11):875-81. https:// doi.org/10.1055/s-0031-1280776

[24] Chmura P, Konefał M, Kowalczuk E, Andrzejewski M, Rokita A, Chmura J. Distances covered above and below anaerobic threshold by professional football players in different competitive conditions. CEJSSM. 2015;10(2):25-31.

[25] Garcia-Aliaga A, Marquina M, Cordon-Carmona A, Sillero-Quintana M, de la Rubia A, Refoyo Roman I. Comparative analysis of soccer performance intensity of the pre-post-lockdown COVID-19 in LaLigaTM. Int J Environ Res Public Health. 2021;18(7):3685. 10.3390/ijerph18073685

[26] Guerrero-Calderon B. The effect of short-term and long-term coronavirus quarantine on physical performance and injury incidence in high-level soccer. Soccer \& Society. 2021;22(1-2):85-95. 10.1080/14660970.2020.1772240

[27] Tlip M, Thaller S. Covid-19 has turned home advantage into home disadvantage in the German Soccer Bundesliga. Fornt Sports Act Living. 2020;2:593499. https://doi.org/10.3389/fspor.2020.593499 